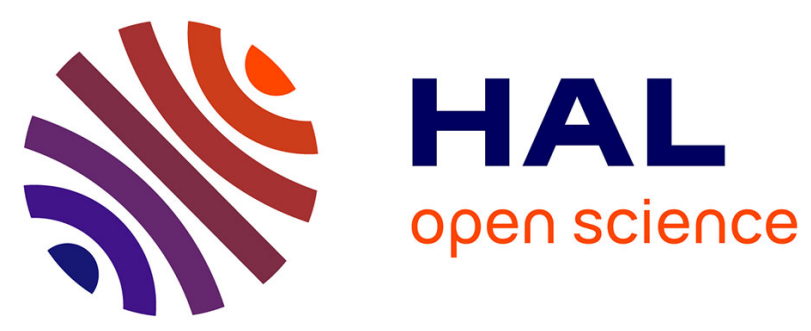

\title{
Food pickiness in the elderly: Relationship with dependency and malnutrition
}

Isabelle Maitre, Virginie van Wymelbeke, Marion Amand, Evelyne Vigneau, Sylvie Issanchou, Claire Sulmont-Rossé

\section{- To cite this version:}

Isabelle Maitre, Virginie van Wymelbeke, Marion Amand, Evelyne Vigneau, Sylvie Issanchou, et al.. Food pickiness in the elderly: Relationship with dependency and malnutrition. Food Quality and Preference, 2014, 32 (Part B), pp.145-151. 10.1016/j.foodqual.2013.04.003 . hal-01215782

\section{HAL Id: hal-01215782 \\ https://hal.science/hal-01215782}

Submitted on 16 Apr 2021

HAL is a multi-disciplinary open access archive for the deposit and dissemination of scientific research documents, whether they are published or not. The documents may come from teaching and research institutions in France or abroad, or from public or private research centers.
L'archive ouverte pluridisciplinaire HAL, est destinée au dépôt et à la diffusion de documents scientifiques de niveau recherche, publiés ou non, émanant des établissements d'enseignement et de recherche français ou étrangers, des laboratoires publics ou privés. 


\section{Food pickiness in the elderly: relationship with dependency and malnutrition}

I. Maitre ${ }^{1}$, V. Van Wymelbeke ${ }^{2}$, M. Amand ${ }^{3}$, E. Vigneau ${ }^{3}$,
S. Issanchou ${ }^{4,5,6}$,
C. Sulmont-Rossé 4,5,6 $^{4}$

${ }^{1}$ LUNAM Université, Groupe ESA, UPSP GRAPPE, Angers, France

${ }^{2} \mathrm{CHU}$, Unité de recherche service de médecine gériatrique, Dijon, France

${ }^{3}$ LUNAM Université, ONIRIS, Unité de Sensométrie et Chimiométrie, Nantes, France

${ }^{4}$ CNRS, UMR6265 Centre des Sciences du Goût et de l'Alimentation, Dijon, France.

${ }^{5}$ INRA, UMR1324 Centre des Sciences du Goût et de l'Alimentation, Dijon, France.

${ }^{6}$ Université de Bourgogne, UMR Centre des Sciences du Goût et de l'Alimentation, Dijon, France.

Corresponding author: i.maitre@groupe-esa.com, 33(0)2 41235555

\section{Abstract}

Among factors contributing to malnutrition in the elderly, the present study aimed at assessing the impact of food selectivity (also referred as food "pickiness") on the nutritional status of the elderly. A survey with 559 French people over 65 years old was conducted to collect data on food selectivity, dependency and nutritional status. Food selectivity was assessed by asking respondents to tick each food they dislike among a list of familiar foods. Since some foods could be ticked as disliked because elderly people experience physical difficulties in eating these foods, the survey also included self-report assessment about difficulties encountered when eating. Results showed that an increase of food selectivity is correlated with an increase of malnutrition risk, parallel to the effect of eating difficulties on malnutrition. It seems that the eating difficulties have a stronger impact on malnutrition than the food selectivity. However, the prevalence of food selectivity appears to be higher than the 
prevalence of eating difficulties. Furthermore, we observed that food selectivity increased as dependency increased. Given the fact that food selectivity may increase the risk of malnutrition, and that the number of "picky" eaters is far from being negligible in nursing homes, it seems worthwhile to screen for pickiness when elderly people become culinary dependent (delegation of food-related activities to a caregiver or a home helper, meal home-delivery by a catering service, nursing homes). It may give an opportunity to improve food care dedicated to these persons and in fine to prevent malnutrition.

\section{Highlights}

$23 \%$ of the elderly are picky eaters, and $36 \%$ among nursing home sample.

An increase of food selectivity is correlated with an increase of malnutrition risk.

Food selectivity in the elderly increases as dependency increases.

$46 \%$ of culinary dependent elderly were malnourished or at risk of malnutrition

We developed a tool to measure food selectivity easy to administrate in the French elderly

\section{Keywords}

food selectivity; elderly; dependence; nutritional status; Body Mass Index; eating difficulties. 


\section{Introduction}

Within the context of an ageing population, malnutrition appears today as a major public health stake. Malnutrition results from an insufficient and/or inadequate nutritional intake which causes different deleterious effects such as muscle wasting and impaired body defenses. In the elderly, malnutrition causes or worsens a state of frailty and/or dependency, and contributes to the development of morbidities. It is also associated with a worsening of the prognosis of underlying diseases and increases the risk of death (Corti, Guralnik, Salive, \& Sorkin, 1994; Ferry, 2011; Wallace, Schwartz, LaCroix, Uhlmann, \& Pearlman, 1995). According to the HAS (2007), 4 to $10 \%$ of elderly people living at home are malnourished. However, the prevalence of malnutrition rises up to 15 to $38 \%$ for elderly people living in nursing home and $70 \%$ for those in geriatric hospitals. The reasons for malnutrition are multifactorial (Donini, 2003; Elsner, 2002; Hays \& Roberts, 2006). In fact, the ageing process, even when normal, is associated with several modifications such as physiological, psychological, economic and social that may impact on nutritional status. Among those factors, the aim of the present study was to assess the impact of food "pickiness", also referred to as food selectivity or fussiness, on the nutritional status of the elderly.

As pointed out by Potts and Wardle (1998), there is a distinction between rejection of a novel food (food neophobia) and rejection of a familiar food. The latter should be referred to as food "pickiness". Food pickiness has been studied both in the children and in the adult population, either by using self-report questionnaires (Carruth, Ziegler, Gordon, \& Barr, 2004; Mascola, Bryson, \& Agras, 2010; Raudenbush, Van Der Klaauw, \& Frank, 1995) or by using food attitude questionnaires (Birch et al., 2001; Kauer, 2002; Mascola et al., 2010; Monnery-Patris, 2009; Smith, Roux, 
Naidoo, \& Venter, 2005; Smith, 1988). In some studies, food pickiness has also been assessed by asking respondents to tick each food they dislike among a list of familiar foods (Frank \& van der Klaauw, 1994; Raudenbush et al., 1995). Despite it was often stated that food pickiness should affect nutritional status, this hypothesis was barely studied and remained controversial (see Dovey, Staples, Gibson and Halford (2008) for a review). In fact, Galloway, Fiorito, Lee and Birch (2005) reported that picky children had lower intakes of vitamin E, folate and fibre and this could be related to a lower consumption of fruits and vegetables compared to non-picky children. Marchi and Cohen (1990) observed that picky eaters have lower Body Mass Index (BMI) than non-picky eaters. However, other research groups have failed to observe such relationship between pickiness and BMI (Carruth \& Skinner, 2000; Kauer, 2002).

Regarding the elderly population, we hypothesized that food pickiness may be a considerable problem because it can be an aggravating factor of malnutrition by restricting diet. Such impact of pickiness may even be worse for elderly people who need help for food related activities. Food dependency usually occurs after a physical or psychological break-down. At home, food dependency can range from delegation of food-related activities such as shopping or cooking to a caregiver, to meal homedelivery by a catering service. Ultimately, for elderly people who live in a nursing home, all meals are planned and provided by the catering service of the institution. When dependent for food, elderly people have to face food choices made by a third party, which may be even more difficult for picky eaters.

To challenge these hypotheses, we designed a quick and easy tool to measure pickiness eating among an elderly - and thus frail - population. Rather than using a self-report questionnaire for which a social desirability bias may affect responses (elderly people may have difficulty in acknowledging themselves as "picky"), we 
asked respondents to tick each food they dislike among a list of familiar foods. Such method was called "list heuristic" by Potts and Wardle (1998). Among others, these authors have pointed out that the nature of foods included in the list was not of great importance while they recommended not using a too small number of items in it. In line with Potts and Wardle (1998) work, we considered that the higher the number of foods ticked as disliked, the pickier the respondent is. However, as Kauer (2002) pointed out that picky adults consider themselves as "selective" rather than "picky", we chose to refer the number of disliked foods as a "selectivity" score.

A survey with people over 65 years old was conducted to collect data on food selectivity, dependency and nutritional status in order to explore the link between these variables. Since some foods could be ticked as disliked because elderly people experience physical difficulties in eating these foods, the survey also included selfreport assessment about dental status and difficulties encountered when eating.

\section{Material and Methods}

\subsection{Aupalesens survey}

The Aupalesens survey is a study of eating behaviour and dependency in the French elderly. In 2011, 559 participants older than 65 years old (65-99 years old, 387 women, 172 men) were recruited among four categories ranging from a high level of autonomy to a high level of dependency. These four categories were defined prior to the survey as follows: category 1 , elderly people living independently at home; category 2, elderly people living at home with help unrelated to food activity (housekeeping; gardening; personal care); category 3, elderly people living at home 
with help including help related to food activity (food purchasing; cooking; home meal delivery); category 4, elderly people living in a nursing home.

The survey was conducted in four French cities and their suburbs (Angers, Brest, Dijon, Nantes). To be recruited, candidates had to meet the following criteria: older than 65 years old; not suffering from an acute pathological episode at the time of the survey; not suffering from congenital anosmia neither from an anosmia due to head injury; not subject to food allergies; not on a diet prescribed by a doctor; not scoring below 20 in the Mini Mental Scale Examination (MMSE; Folstein, Folstein \& McHugh, 1975; this questionnaire screens for cognitive impairment). A brief interview was carried out with each candidate to check completion of inclusion criteria. The experimental protocol of the survey was approved by the French Ethical Research Committee (CPP Est I, Dijon, \#2010/42, AFSSAPS\# 2010-A01079-30). In accordance with the rules of ethics, all participants received written and oral information on the survey before signing a consent form.

Respondents took part in two sessions of about 90-minutes each during which extensive medical, nutritional, psychological, sociological and sensory data were collected on the basis of tests and questionnaires. Face-to-face interviews were run by six experimenters (all women) that followed a 1-day training session. Only data related to nutritional status, food selectivity and eating difficulty in addition to background information such as dependency category, age and gender are reported here. 


\subsection{Measurements}

\subsubsection{Nutritional status}

Respondents completed the Mini Nutritional Assessment@ (MNA; Guigoz, Lauque \& Vellas, 2002), a validated screening tool on a scale of 30 points that identifies elderly persons who are nourished normally (score $>23.5$ ), at risk for malnutrition (score between 17-23.5) or malnourished (score < 17). It comprises 18 questions and relies on four dimensions: anthropometric assessment including Body Mass Index (BMI) measurement, global evaluation, dietetic assessment, and subjective assessment. Anthropometric measurements were done by the six trained experimenters.

\subsubsection{Food selectivity}

Respondents were asked to tick each food item they dislike among a list of 71 familiar products which includes both raw foods and dishes from the following categories: starter, meat, fish, egg, garnish, dairy products, desserts, bread, and beverage (Table 1). The selectivity score is the number of disliked food items among the list of 71 items. This list has been designed thanks to the help of health care professionals and food manufacturers delivering food for nursing homes. A first list of 80 items was assessed through a preliminary study run with 60 elderly participants who did not participate in the present study. Nine items were removed because they were disliked by more than $20 \%$ of the sample. The food selectivity questionnaire was self-administrated except for people who had difficulty in reading and/or writing.

\subsubsection{Eating difficulties.}

Eating difficulties were assessed through a generic question and four specific questions. Firstly, participants were asked to indicate whether eating is "very difficult", 
"difficult", "not very easy", "easy" or "very easy". Secondly, they had to indicate whether they experienced difficulty in cutting the food, in putting the food in the mouth, in chewing the food and in swallowing the food ("yes", "somewhat yes", "somewhat no", "no"). They were also asked to indicate whether they were dentate with or without partial dentures, edentulous with partial or complete denture, edentulous without denture.

\subsection{Data treatment}

For each respondent, a selectivity score was computed by counting the number of foods ticked as disliked. Statistical analyses were conducted using STATGRAPHICS Plus (5.1). As some independent variables were categorical (e.g., dependency category, gender) and other continuous (e.g., age, selectivity score), we performed analyses of covariance (ANCOVA) with the General Linear Model (GLM) procedure of STATGRAPHIC (type III sum of squares). Least-squares means (LS-means) were computed for each factor and submitted to multiple comparisons analysis thanks to the Newman-Keuls method. All the results reported here were significant at a level of

0.05 unless otherwise stated. Means $(M)$ are given with associated standard deviation $(S D)$. 
Table 1. List of 71 products to be ticked if disliked

\begin{tabular}{|c|c|}
\hline \multirow[t]{11}{*}{ Starters } & Betterave cuite (cooked red beetroot) \\
\hline & Carottes râpées vinaigrette (raw carrots with vinaigrette) \\
\hline & concombres (cucumbers) \\
\hline & avocat (avocado) \\
\hline & Taboulé (tabbouleh) \\
\hline & Oeufs durs macédoine (hard boiled eggs \& mixed diced vegetables) \\
\hline & Céleri rémoulade (grated celeriac in a mayonnaise dressing) \\
\hline & Melon (melon) \\
\hline & Asperges sauce mousseline (asparagus mousseline sauce) \\
\hline & Tomates Mimosa (tomato Mimosa) \\
\hline & Salade piémontaise (piémontaise salad (tomatoes, potatoes, hard boiled eggs)) \\
\hline \multirow[t]{6}{*}{ Meats } & Bœuf (beef) \\
\hline & Porc (pork) \\
\hline & Poulet (chicken) \\
\hline & Veau (veal) \\
\hline & Agneau (lamb) \\
\hline & Lapin (rabbit) \\
\hline \multirow{11}{*}{$\begin{array}{l}\text { Meat } \\
\text { cooked } \\
\text { dishes }\end{array}$} & Bœuf aux carottes (beef and carrots) \\
\hline & Pot au feu (pot-au-feu) \\
\hline & Poulet basquaise (chicken with tomatoes and peppers) \\
\hline & Petit salé aux lentilles (salty ham and lentils) \\
\hline & Hachis parmentier (Sheherd's pie) \\
\hline & Blanquette de veau (blanquette of veal) \\
\hline & Bœuf bourguignon (Burgundy beef stew) \\
\hline & Plats cuisinés exotiques (exotic cooked dishes) \\
\hline & Poulet au curry, carottes, oignons (chicken curry with carrots and onions) \\
\hline & Veau braise aux endives (braised veal with endives) \\
\hline & Porc aux pruneaux et petits légumes (pork with prune and vegetables) \\
\hline \multirow[t]{2}{*}{ Fishes } & Poisson au court bouillon (fish in a court-bouillon) \\
\hline & Paella (paella) \\
\hline \multirow[t]{5}{*}{ Eggs } & Omelette (omelette) \\
\hline & OEufs durs (hard boiled eggs) \\
\hline & OEufs au plat (fried eggs) \\
\hline & CEufs pochés (poached eggs) \\
\hline & CEufs brouillés (scrambled eggs) \\
\hline \multirow[t]{4}{*}{ Garnish } & Poireaux (leeks) \\
\hline & Lentilles (lentils) \\
\hline & Carottes cuites (cooked carrots) \\
\hline & Haricots verts (green beans) \\
\hline
\end{tabular}




\begin{tabular}{|c|c|}
\hline & Pommes de terre vapeur (steam cooked potatoes) \\
\hline & Courgettes (courgettes/ zucchinis) \\
\hline & Poivrons (sweet pepper) \\
\hline & Gratin dauphinois (Gratin dauphinois) \\
\hline & Riz (rice) \\
\hline & Pâtes (pasta) \\
\hline \multirow{14}{*}{$\begin{array}{l}\text { Dairy } \\
\text { products } \\
\text { and } \\
\text { desserts }\end{array}$} & Fromage fondu (proceeded cheese) (as Vache-qui-rit ${ }^{\circledR}$ or Kiri®) \\
\hline & Fromage à pâte molle (soft cheese) (as camembert) \\
\hline & Fromage type Emmental (cheese as emmental) \\
\hline & Fromage type (cheese as) St Paulin, Chaussée aux moines, Cheddar \\
\hline & Compote (fruit puree) \\
\hline & Tartes aux fruits (fruit pies) \\
\hline & Yaourt nature (plain yoghourt) \\
\hline & Crème au chocolat (chocolate cream) \\
\hline & Crème à la vanille (vanilla cream) \\
\hline & Crème au caramel (caramel cream) \\
\hline & Crème pralinée (praline cream) \\
\hline & Clafoutis (clafoutis) \\
\hline & Brioche (brioche) \\
\hline & Biscuit type petit beurre (butter biscuits) \\
\hline \multirow[t]{9}{*}{ Bread } & Pain blanc (white bread) \\
\hline & Pain bis ou de campagne (brown bread or country bread) \\
\hline & Pain complet ou semi-complet (whole-grain bread or middle whole-grain bread) \\
\hline & Pain aux graines (seed bread) \\
\hline & Pain de mie (sandwich bread) \\
\hline & Baguette \\
\hline & Pain individuel (individual bread) \\
\hline & Pain tranché (sliced bread) \\
\hline & Biscotte (zwieback) \\
\hline \multirow[t]{3}{*}{ Beverages } & Lait (milk) \\
\hline & Lait aromatisé (flavoured milk) \\
\hline & Chocolat chaud (hot chocolate) \\
\hline
\end{tabular}

\section{Results}

\subsection{Sample characteristics}

Five-hundred and fifty-nine participants were included in the survey. Two-hundred and eighty-nine people were interviewed in category 1 (65 to 90 yrs; mean age: 74 
yrs; 198 women, 91 men), 74 in category 2 (68 to 92 yrs; mean age: 81 yrs; 54 women, 20 men), 101 in category 3 (67 to $97 \mathrm{yrs}$; mean age:85 yrs; 67 women, 34 men) and 95 in category 4 (69 to $99 \mathrm{yrs}$; mean age:87 yrs; 68 women, 27 men). As expected, age and malnutrition increased with dependency categories [age: $F_{(3,558)}=161.4 ; p<.001$; malnutrition: Chi2 $\left.=107.4 ; p<.001\right]$. Female/male ratio was not significantly different between categories $\left[C h i^{2}=1.2 ; p=.75\right]$. According to the MNA score, the proportion of people that were malnourished or at risk of malnourishment was equal to $8 \%$ in the first category (people living at home without help), $16 \%$ in the second one (people living at home with help unrelated to food activities), and reaches $46 \%$ in the last two categories (i.e., people living at home with help related to food activities and people living in a nursing home).

\subsection{Selectivity scores. Impact of age, gender and dependency}

Figure 1 depicts the distribution of selectivity scores within the whole panel. Selectivity scores varied from $0(n=34)$ to 40 out of a total of 71 food items, with a mean of $8.7(S D=7.6) .25 \%$ of the sample scored higher than 13 and $10 \%$ scored higher than 20 .

Figure 1. Distribution of selectivity scores within the whole panel.

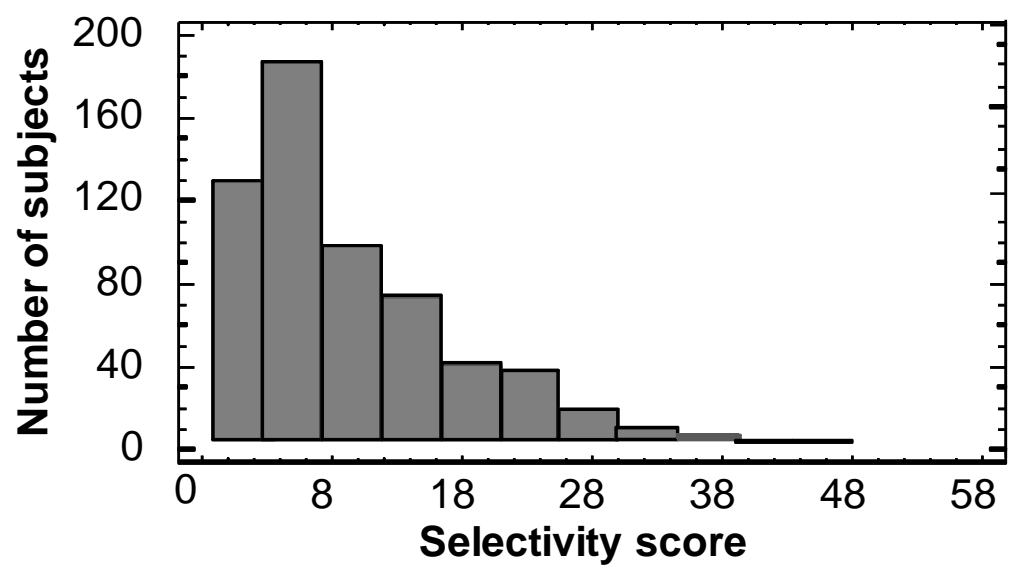


The selectivity scores were submitted to an ANCOVA with gender, dependency category and age as independent variables. As interactions were not significant, they were removed from the model (category $\times$ gender: $p=.75$; category $\times$ age: $p=.21$; genderxage: $p=.57)$. Results showed a significant effect of dependency category $\left[F_{(3,553)}=8.75 ; p<.001\right]$ while no effect of age $\left[F_{(1,553)}=1.37 ; p=.24\right]$ nor of gender $\left[F_{(1,553)}=0.02 ; p=.88\right]$ were observed. According to post-hoc analyses, elderly people living in a nursing home (category 4) were more selective than elderly people living at home with help related to food activity (category 3), who in turn were more selective than elderly people living independently at home (category 1 ). Selectivity scores of elderly people living at home with help unrelated to food activity (category 2) were intermediate and not significantly different compared to the scores of category 1 and category 3 (Figure 2). To sum up, when adjusted for age and gender, selectivity increases as elderly people become more dependent for food related activities. Figure 2 also pointed out an increase of between-subject variation with dependency level.

Figure 2. Selectivity score: Boxplot with outlier for each dependency category

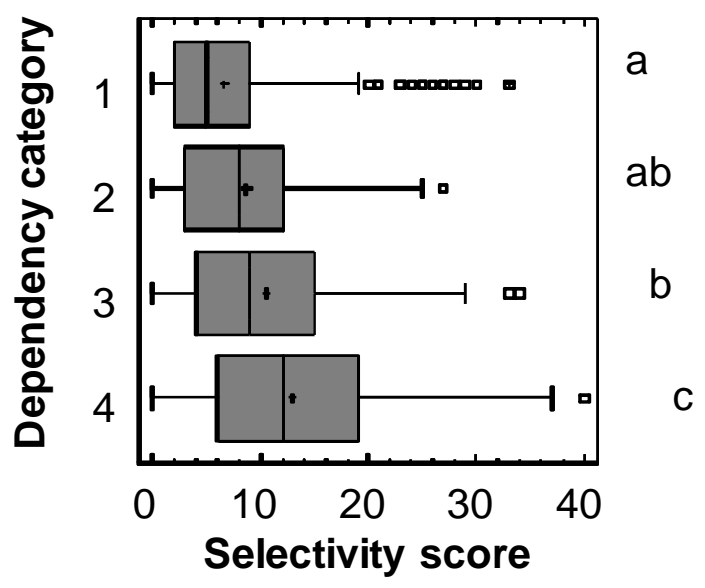




\subsection{Eating difficulties}

Over the entire panel, only $8 \%$ of the respondents $(n=44)$ reported in the generic question suffering from moderate to high difficulty when eating. According to a Student $t$ test, respondents who reported difficulty when eating were older ( $M=82.6$ years old; $S D=7.2)$ than respondents who reported no difficulties $(M=78.7$ years old; $S D=8.2)[t=-3.05 ; p<0.01]$. Those with difficulties were also more dependent than those without difficulties. $3 \%, 9 \%, 11 \%$ and $18 \%$ of respondents in categories 1 to 4 respectively reported difficulties when eating $\left[c h i^{2}=23.70 ; p<.001\right]$. No gender effect was observed for this variable $\left[c h i^{2}=0.25 ; p=0.62\right]$.

$57 \%$ of the respondents who reported eating difficulties reported difficulty in chewing the food while they were only $18 \%, 34 \%$ and $16 \%$ respectively to report difficulty in swallowing, in cutting and in bringing the foods to the mouth. Furthermore, $48 \%$ of the respondents who reported eating difficulties were missing some teeth (they had a partial dentition without denture or they were edentulous with a partial denture or no denture). Only $23 \%$ of the respondents who reported no eating difficulties were in the same situation with regard to dentition $\left(c h i^{2}=13.1, p<0.001\right)$.

As the generic question about eating difficulties seems to adequately reflect an overall feeling of the respondents about eating, only this question was conserved for the next analyses.

\subsection{Impact of selectivity and eating difficulties on nutritional status}

Nutritional scores computed from the Mini-Nutritional Assessment questionnaire (MNA scores) were submitted to an ANCOVA with dependency category, eating difficulties (uneasy; easy), age and selectivity as independent variables. As 
interactions were not significant, they were removed from the model. Results showed a significant effect of dependency category $\left[F_{(3,553)}=28.5 ; p<.001\right]$, of eating difficulties $\left[F_{(1,553)}=66.0 ; p<.001\right]$ and of selectivity $\left[F_{(1,553)}=17.9 ; p<.001\right]$. No significant effect of age, once adjusted to the other effects, was observed $\left[F_{(1,553)}=0.0 ; p=.98\right]$. Figure 3 depicts the relationship between nutritional and selectivity scores for each dependency category (Figure 3.a), and for respondents who reported difficulties when eating versus respondents who reported no difficulties (Figure 3.b).

Figure 3. Regression lines between MNA score and selectivity score by dependency category (a) and eating difficulties level (b).

(a)

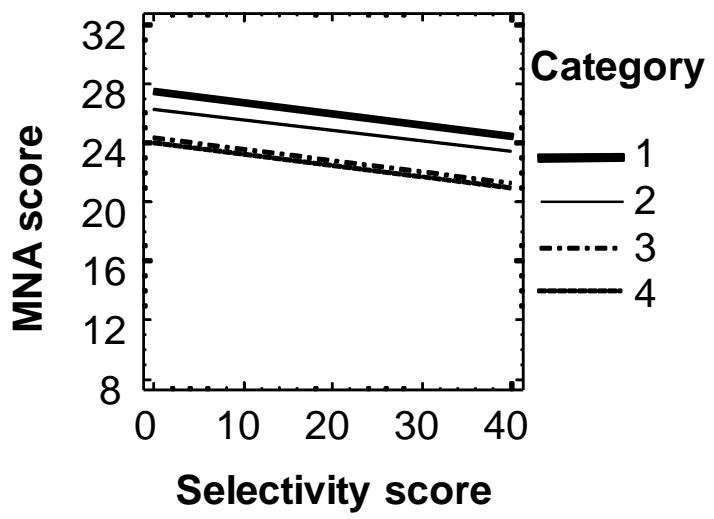

Adjusted $R^{2}=29.5 \%$ (b)

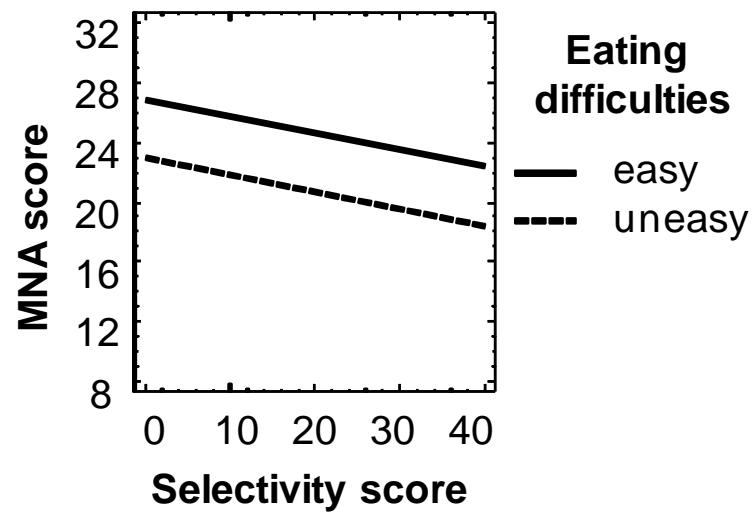

Adjusted $\mathrm{R}^{2}=21.3 \%$

This figure shows that MNA score decreases when dependency increases (3.a) or when difficulties in eating occur (3.b). According to post-hoc analyses, MNA scores of categories 3 and 4 (category 3: $L S m e a n=21.9$; $S D=0.3$; category 4: $L S m e a n=22.2$; $S D=0.4)$ are significantly lower than the one of category $2(L S m e a n=24.0 ; S D=0.4)$, itself lower than the one of category 1 ( $L S m e a n=24.9 ; S D=0.3)$. At the same time, the estimated coefficient associated with the variable eating difficulties is -1.63 , meaning 
that when difficulties in eating are experienced, the MNA score should decrease by 1.63 points. Thus, respondents who reported medium to high difficulties when eating are associated with a lower MNA score $(L S m e a n=21.8 ; S D=0.14)$ than respondents who reported no difficulties when eating ( $L S m e a n=25.2 ; S D=0.4)$.

Independently of these two variables, an increase of selectivity score is also correlated with a decrease of MNA score. The estimated coefficient associated with the variable selectivity is -0.06 : when the selectivity score increases by ten points, the MNA score should decrease by 0.6 points, given that the mean value of the observed MNA is 24.1. This is illustrated in figure 3: an increase of selectivity is associated with a decrease of MNA score, within all dependency categories (Figure 3.a) and for respondents who both reported no difficulties in eating and respondents who reported difficulties in eating (Figure 3.b).

The same linear model was applied to respondents' BMI values. As the interaction category $\times$ age was significant $\left[F_{(3,549)}=5.0 ; p<.01\right]$, it was included in the final model. It appears that BMI was significantly associated with eating difficulties $\left[F_{(1,549)}=15.5\right.$; $p<.001]$ but not with food selectivity $\left[F_{(1,549)}=2.7 ; p=.10\right]$. According to post-hoc analyses, respondents who reported medium to high difficulties when eating are associated with a lower BMI ( $L S m e a n=26.6 ; S D=0.8$ ) than respondents who reported no difficulties when eating ( $L S m e a n=29.5 ; \quad S D=0.3)$. A significant effect of dependency category $\left[F_{(3,549)}=6.2 ; p<.0001\right]$ and of age $\left[F_{(1,549)}=18.4 ; p<.0001\right]$ was also observed, meaning that BMI decreased with dependency and age. 


\section{Discussion}

To our knowledge, the present study is the first one to explore food selectivity in an elderly population. To achieve this goal, we have succeeded in designing a selectivity questionnaire well-accepted by the respondents and easy to administrate with such a frail population. Moreover, the range of variation in the selectivity score computed from this questionnaire was large enough to reveal inter-individual differences. In particular, we observed that $23 \%$ of the sample disliked more than $20 \%$ of the food items and thus can be described as rather picky. This result was not necessarily expected as respondents were born around the Second World War. According to popular belief, this population, who suffered from food restrictions, learned to finish whatever was on their plate and to not complain about food.

The main result of the present study is that an increase of food selectivity is correlated with an increase of malnutrition risk, parallel to the effect of eating difficulties on malnutrition. Interestingly, no impact of food selectivity was observed on respondents' Body Mass Index (BMI) while an increase in eating difficulties was correlated with a decrease of respondents' BMI. This suggests different mechanisms behind these effects. On the one hand, one could argue that food selectivity leads to a monotonous and unbalanced diet, which in turn leads to a decline of nutritional status. Despite no studies yet in place for an elderly population, several authors observed that food selectivity was associated with an unbalanced diet in children (Arimond \& Ruel, 2004; Carruth et al., 1998; Carruth et al., 2004; Galloway et al., 2005; Mascola et al., 2010). However, it is acknowledged that for the elderly, a lack of dietry variety leads to an imbalance between nutritional supplies and the body's requirements, which in turn deteriorates the nutritional status (Arimond \& Ruel, 2004;

Bernstein et al., 2002; Hays \& Roberts, 2006; WHO, 2003) and increases morbidity 
(Kant, Schatzkin, Harris, Ziegler, \& Block, 1993). On the other hand, it could be put forward that eating difficulties decrease food intake by causing pain and reducing eating motivation. Intake decrease may in turn lead to weight lost and malnutrition risk (Lamy, Mojon, Kalykakis, Legrand, \& Butz-Jorgensen, 1999; Lee, Huang, \& Wahlqvist, 2010; Westergren, Lindholm, Mattsson, \& Ulander, 2009; Westergren, Unosson, Ohlsson, Lorefält, \& Hallberg, 2002; Woo, Ho, Lau, \& Yuen, 1994). These hypothetical pathways, namely a rather "qualitative" pathway between food selectivity and malnutrition, and a rather "quantitative" pathway beween eating difficulties and malnutrition, are depicted in Figure 4. In spite of the fact that this model deserves further studies to be validated, we do hope that it offers a theoretical framework for these further studies.

Figure 4. Hypothetical pathways between food selectivity, eating difficulties and malnutrition risk.

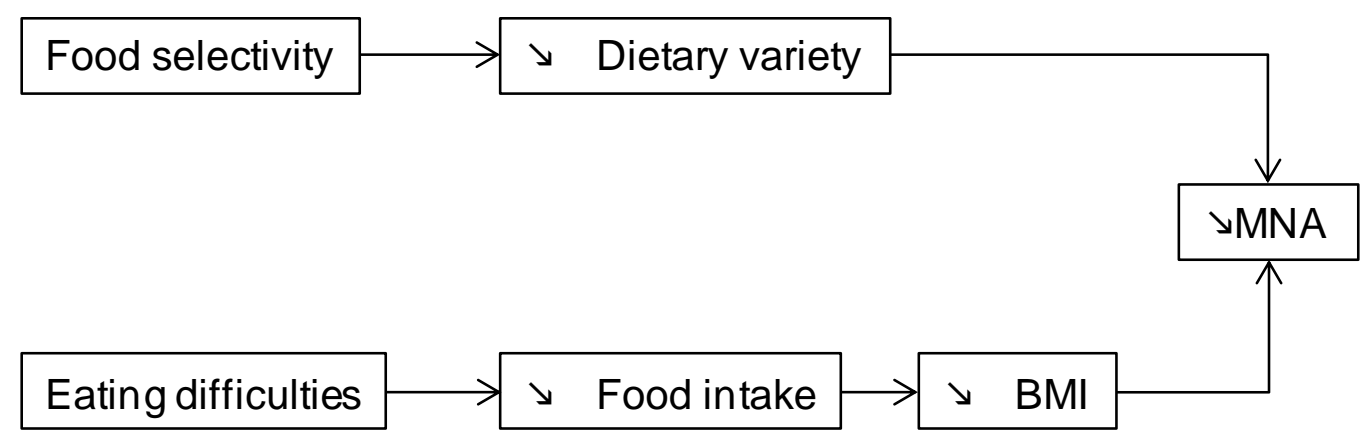

It seems that the eating difficulties have a stronger impact on malnutrition than the food selectivity, even if direct comparisons between a qualitative variable and a quantitative variable are subject to caution. In fact, respondents who reported medium to high difficulties when eating scored 3 points lower on the MNA questionnaire than respondents who reported no difficulties. At the same time, an 
increase of 10 points for the selectivity score was related to a decrease of only 0.6 points for the MNA score. However, in our sample, the prevalence of food selectivity appears to be higher than the prevalence of eating difficulties. Despite the fact that our data does not allow for setting a "threshold" (namely a score above which people could be categorized as "picky"), we observed that $23 \%$ of our sample disliked at least $20 \%$ of the food items proposed in the list, while only $8 \%$ of the respondents reported medium to high difficulty when eating. This pleads for taking into account food selectivity, parallel to other factors, when one is looking at the etiology of malnutrition.

When planning this research, we assumed that the impact of food selectivity on nutritional status would be worse for elderly people who delegate all or part of foodrelated activities to a third party (i.e., for the categories 3 and 4 of the present study). Moreover, in the present survey, we observed a drastic increase in malnutrition risk with culinary dependence: $46 \%$ of respondents who were culinary dependent were malnourished or at risk of malnutrition while this proportion reached only $8 \%$ for autonomous elderly people. However, according to the present results, dependency does not seem to worsen the impact of selectivity on malnutrition among culinary dependent people (no interaction was observed between the level of dependency and food selectivity). Nevertheless, we observed that food selectivity increased as dependency increased (Figure 2). In fact, $10 \%$ of the respondents living at home without help (category 1) disliked at least $20 \%$ of the food items but this proportion reaches $36 \%$ for respondents living in a nursing home (category 4 ). As our study cannot allow for determining the causal sense of the relationship between dependency and food selectivity, two hypotheses could be formulated. First, food selectivity may predispose to malnutrition by a lack of dietary variety. This, in turn, 
may contribute to a decline of functional capacities and autonomy. Second, dependency, which often appears with an increase of physical and psychological sufferings, may also contribute to the development of food selectivity. At this stage, further studies are needed to discover whether food pickiness is a personality trait, steady over the course of a life time, and/or if it increases with dependency.

As noted by Edfors and Westergren (2012), "Meeting the need for optimal nutritional status for older people living at home requires knowledge of individual preferences and habits, from both their earlier and current lives." Given the fact that food selectivity may increase the risk of malnutrition, and that the number of "picky" eaters is far from being negligible in nursing homes, it seems worthwhile to screen for pickiness when elderly people become culinary dependent. It may give an opportunity to improve food care dedicated to these persons and in fine to prevent malnutrition. Such screening requires appropriate tools as elderly persons seldom complain about food (CLCV, 2012; Sidenvall, 1999). In fact, as pointed out by Sidenvall (1999), "elderly patients were grateful for food and everything that was done for them, and as a result they remained silent about disgusting food and unfitting caring actions; as an enrolled nurse said: 'She always says it's all right when you ask'". In this sense, using a heuristic list (Potts \& Wardle, 1998) as the one used in the present study may offer an interesting perspective to treat this problem.

\section{Conclusion}

The present survey showed that an increase of food selectivity is correlated with an increase of malnutrition risk, parallel to the effect of eating difficulties on malnutrition. It seems that the eating difficulties have a stronger impact on malnutrition than the 
food selectivity, However, the prevalence of food selectivity appears to be higher than the prevalence of eating difficulties.

Despite popular belief, French people older than 65 years of age are not necessarily eager to eat whatever is on their plate. Instead, some of them are rather "picky", especially when dependency occurs. At this stage, further research is needed to disentangle the impact of food selectivity on dependency from the impact of dependency on food selectivity. Nonetheless, the relationship between food selectivity and malnutrition challenges catering services dedicated to the elderly to move from a collective answer toward a more tailored system, better suited to the food preferences of each individual.

\section{Acknowledgments}

This study is part of AUPALESENS - Improving pleasure of elderly people for better aging and for fighting against malnutrition - funded by the French National Research Agency (ANR - ALID call). The authors thank Géraldine Chaillot for running the survey in Angers; Elodie Caumon, Celia Crema for running the survey in Dijon; Marion Provost for running the survey in Nantes; Julia Ménard and Claire Vaugeois

(Défi Santé Nutrition) for running the survey in Brest; Ronan Symoneaux, Jérémy Tavares and Valerie Feyen for designing and scanning Fizz questionnaires; Fiona Casey for providing language help.

\section{Bibliography}

Arimond, M., \& Ruel, M. T. (2004). Dietary diversity is associated with child nutritional status: Evidence from 11 demographic and health surveys. The Journal of Nutrition, 134(10), 25792585. 
Bernstein, M. A., Tucker, K. L., Ryan, N. D., O'Neill, E. F., Clements, K. M., Nelson, M. E., et al. (2002). Higher dietary variety is associated with better nutritional status in frail elderly people. Journal of the American Dietetic Association, 102(8), 1096-1104.

Birch, L. L., Fisher, J. O., Grimm-Thomas, K., Markey, C. N., Sawyer, R., \& Johnson, S. L. (2001). Confirmatory factor analysis of the Child Feeding Questionnaire: a measure of parental attitudes, beliefs and practices about child feeding and obesity proneness. Appetite, 36(3), 201-210.

Carruth, B. R., Skinner, J., Houck, K., Moran, J., 3rd, Coletta, F., \& Ott, D. (1998). The phenomenon of "picky eater": a behavioral marker in eating patterns of toddlers. J Am Coll Nutr, 17(2), 180-186.

Carruth, B. R., \& Skinner, J. D. (2000). Revisiting the "picky/fussy" eater phenomenon: Neophobic behaviours of young children. Journal of the American College of Nutrition, 19, 771-780.

Carruth, B. R., Ziegler, P. J., Gordon, A., \& Barr, S. I. (2004). Prevalence of picky eaters among infants and toddlers and their caregivers' decisions about offering a new food. Journal of the American Dietetic Association, 104, Supplement 1(0), 57-64.

CLCV. (2012). enquête sur l'alimentation des personnes âgées. CLCV, http://www.clcv.org/images/CLCV/user_upload/com_press/dossiers/CONSO-DP-CLCValimentation-seniors_02022012.pdf

Corti, M. C., Guralnik, J. M., Salive, M. E., \& Sorkin, J. D. (1994). Serum albumin level and physical disability as predictors of mortality in older persons. JAMA, 272(13)(0098-7484 (Print)), 1036-1042.

Donini, L., Savina, C, Cannella, C. (2003). Eating habits and appetite control in the elderly: the anorexia of aging. Int Psychogeriatr. 2003 Mar;15(1):73-87.

Dovey, T. M., Staples, P. A., Gibson, E. L., \& Halford, J. C. G. (2008). Food neophobia and 'picky/fussy' eating in children: A review. Appetite, 50(2-3), 181-193.

Edfors, E., \& Westergren, A. (2012). Home-Living Elderly People's Views on Food and Meals. J Aging Res, 2012, 761291.

Elsner, R. J. F. (2002). Changes in eating behavior during the aging process. Eating Behaviors, 3(1), 15-43.

Ferry, M. (2011). Nutrition / Dénutrition personnes âgées. oral presentation 11/05/05 CNSA. http://www.cnsa.fr/IMG/pdf/Nutrition_denutrition_des_PA.pdf

Folstein, M., Folstein, S., \& McHugh, P. (1975). Mini-Mental-State: a practical method for grading cognitive state of patients for the clinician. J Psychiatr Res, 12, 189 - 198.

Frank, R. A., \& van der Klaauw, N. J. (1994). The Contribution of Chemosensory Factors to Individual Differences in Reported Food Preferences. Appetite, 22(2), 101-123.

Galloway, A. T., Fiorito, L., Lee, Y., \& Birch, L. L. (2005). Parental pressure, dietary patterns, and weight status among girls who are "picky eaters". Journal of the American Dietetic Association, 105(4), 541-548.

Guigoz, Y., Lauque, S., \& Vellas, B. J. (2002). Identifying the elderly at risk for malnutrition. The Mini Nutritional Assessment. Clinics in Geriatric Medicine, 18(4), 737-757.

HAS. (2007). Stratégie de prise en charge en cas de dénutrition protéino-énergétique chez la personne âgée. recommandations professionnelles. HAS http://www.hassante.fr/portail/upload/docs/application/pdf/denutrition_personne_agee_2007_-

_recommandations.pdf

Hays, N. P., \& Roberts, S. B. (2006). The anorexia of aging in humans. Physiology \& Behavior, 88(3), 257-266. 
Kant, A. K., Schatzkin, A., Harris, T. B., Ziegler, R. G., \& Block, G. (1993). Dietary diversity and subsequent mortality in the First National Health and Nutrition Examination Survey Epidemiologic Follow-up Study. Am J Clin Nutr, 57(3), 434-440.

Kauer, J. (2002). The range and variation of human food selection: Adult picky eating. Thesis, University of Pennsylvania.

Lamy, M., Mojon, P., Kalykakis, G., Legrand, R., \& Butz-Jorgensen, E. (1999). Oral status and nutrition in the institutionalized elderly. Journal of dentistry, 27(6), 443-448.

Lee, M. S., Huang, Y. C., \& Wahlqvist, M. L. (2010). Chewing ability in conjunction with food intake and energy status in later life affects survival in taiwanese with the metabolic syndrome. Journal of the American Geriatrics Society, 58(6), 1072-1080.

Marchi, M., \& Cohen, P. (1990). Early Childhood Eating Behaviors and Adolescent Eating Disorders. Journal of the American Academy of Child and Adolescent Psychiatry, 29(1), 112117.

Mascola, A. J., Bryson, S. W., \& Agras, W. S. (2010). Picky eating during childhood: A longitudinal study to age 11years. Eating Behaviors, 11(4), 253-257.

Monnery-Patris, S. (2009). L'enfant difficile à table : impact des caractéristiques personnelles et des pratiques familiales. Résultats préliminaires de l'étude Opaline. In I. Danone, XVIIIèmes Rencontres Scientifiques de Nutrition.

Potts, H. W. W., \& Wardle, J. (1998). The List Heuristic for Studying Personality Correlates of Food Choice Behaviour: a Review and Results from Two Samples. Appetite, 30(1), 79-92.

Raudenbush, B., Van Der Klaauw, N. J., \& Frank, R. A. (1995). The Contribution of Psychological and Sensory Factors to Food Preference Patterns as Measured by the Food Attitudes Survey (FAS). Appetite, 25(1), 1-15.

Sidenvall, B. (1999). Meal procedures in institutions for elderly people: a theoretical interpretation. J Adv Nurs, 30(2), 319-328.

Smith, A. M., Roux, S., Naidoo, N. T., \& Venter, D. J. (2005). Food choice of tactile defensive children. Nutrition, 21(1), 14-19.

Wallace, J. I., Schwartz, R. S., LaCroix, A. Z., Uhlmann, R. F., \& Pearlman, R. A. (1995). Involuntary weight loss in older outpatients: incidence and clinical significance. J Am Geriatr Soc, 43(4), 329-337.

Westergren, A., Unosson, M., Ohlsson, O., Lorefält, B., \& Hallberg, I. R. (2002). Eating difficulties, assisted eating and nutritional status in elderly ( $\geqslant 65$ years) patients in hospital rehabilitation. International Journal of Nursing Studies, 39(3), 341-351.

Westergren, A., Lindholm, C., Mattsson, A., \& Ulander, K. (2009). Minimal eating observation form: reliability and validity. J Nutr Health Aging, 13(1), 6-12.

WHO, F. (2003). Diet, nutrition, and the prevention of chronic diseases. WHO technical report series, 916 .

Woo, J., Ho, S., Lau, J., \& Yuen, Y. K. (1994). Chewing difficulties and nutritional status in the elderly. Nutrition Research, 14(11), 1649-1654. 